\title{
Managing chronic lymphocytic leukemia in 2020: an update on recent clinical advances with a focus on BTK and BCL-2 inhibitors
}

\author{
Prithviraj Bose ${ }^{1^{*}}$ Varsha Gandhi (iD ${ }^{1,2^{*}}$ \\ 1 Department of Leukemia, University of Texas MD Anderson Cancer Center, Houston, TX 77030, USA \\ ${ }_{2}$ Department of Experimental Therapeutics, University of Texas MD Anderson Cancer Center, Houston, TX 77030, USA
}

\begin{abstract}
The therapeutic landscape of chronic lymphocytic leukemia (CLL) underwent a paradigm shift in 2014 with the approval of ibrutinib, which binds covalently to the C481 residue of Bruton's tyrosine kinase (BTK) and irreversibly inhibits it. A number of large, phase 3 trials conducted in both the frontline and the relapsed/refractory settings resulted in the approval of ibrutinib for all CLL. Indeed, the role of chemoimmunotherapy in CLL is fast dwindling. The limitations of ibrutinib, e.g. the development of resistance-conferring C481 BTK mutations and the toxicity issues of atrial fibrillation and bleeding, in particular, have also become apparent with longer-term follow-up. This has spurred the development of second-generation, irreversible inhibitors with greater selectivity for BTK and third-generation, reversible BTK inhibitors to address C481 site mutations. The last 3 years have also witnessed enormous growth in the therapeutic role of the B-cell lymphoma 2 (BCL-2) antagonist venetoclax, initially approved (in 2016) only for patients with relapsed, 17p-deleted CLL. Venetoclax, in combination with CD20 antibodies, is currently approved for both treatment-naïve and relapsed/refractory patients, regardless of genomic subtype. Robust results have also been reported for ibrutinib plus venetoclax, and "triple" combinations of a BTK inhibitor, venetoclax, and obinutuzumab are now being pursued. The major questions facing the field at present are how best to select patients for BTK inhibitor monotherapy versus venetoclax/obinutuzumab upfront, what to do after failure of both BTK inhibitor(s) and venetoclax, and the ideal way to integrate measurable residual disease data into decisions regarding treatment choice, duration, and discontinuation.
\end{abstract}

\section{Keywords}

Chronic lymphocytic leukemia, ibrutinib, venetoclax, reversible BTK inhibitors, acalabrutinib, zanubrutinib, obinutuzumab, duvelisib

\section{Peer Review}

The peer reviewers who approve this article are:

1. Jacqueline Barrientos, CLL Research and Treatment Program, Northwell Health Cancer Institute, Hempstead, NY Competing interests: Jacqueline Barrientos received honoraria from Janssen; had a consultancy/advisory role with AbbVie, AstraZeneca, Bayer, Genentech, Gilead, Pharmacyclics LLC, an AbbVie Company, and Sandoz; received research funding from AbbVie, Oncternal Therapeutics, and Pharmacyclics LLC, an AbbVie Company.

2. Francesco Bertoni, Institute of Oncology Research, Università della Svizzera italiana, Bellinzona, Switzerland Competing interests: No competing interests were disclosed. 
*Corresponding author: Varsha Gandhi (vgandhi@mdanderson.org); Prithviraj Bose (pbose@mdanderson.org)

Competing interests: The authors declare that they have no competing interests.

Grant information: V.G. has received research grants from Pharmacyclics, Acerta, AbbVie, AstraZeneca, Gilead, Sunesis, Infinity, Loxo Oncology, and ClearCreek Bio. This work was supported, in part, by the CLL Global Research Foundation award and MD Anderson's CLL Moon Shot program as well as the MD Anderson Cancer Center Support Grant (P30 CA016672) from the National Cancer Institute (National Institutes of Health).

The funders had no role in the study design, data collection and analysis, preparation of the manuscript, and decision to publish it.

Copyright: $\left({ }_{0} 2021\right.$ Gandhi V et al. This is an open access article distributed under the terms of the Creative Commons Attribution License, which permits unrestricted use, distribution, and reproduction in any medium, provided the original work is properly cited.

How to cite this article: Bose $\mathrm{P}$ and Gandhi V. Managing chronic lymphocytic leukemia in 2020: an update on recent clinical advances with a focus on BTK and BCL-2 inhibitors. Faculty Reviews 2021 10:(22) https://doi.org/10.12703/r/10-22

Published: 26 Feb 2021, Faculty Reviews 10:(22) https://doi.org/10.12703/r/10-22 


\section{Introduction}

The emergence of an array of highly effective targeted therapies that exploit several intrinsic vulnerabilities of chronic lymphocytic leukemia (CLL) cells, particularly small molecules that target Bruton's tyrosine kinase (BTK) to interfere with $\mathrm{B}$-cell receptor (BCR) signaling or the anti-apoptotic function of B-cell lymphoma (BCL-2), has transformed the treatment landscape of this disease and made it one of the most gratifying hematologic malignancies to treat. With these unprecedented successes have come new challenges: the costs and unique adverse events (AEs) associated with indefinite BTK blockade, the problem of relapse after "time-limited" (1-2 year) venetoclax/ anti-CD20 monoclonal antibody regimens, the immunemediated AEs observed with the phosphatidylinositol-3-kinase (PI3K) inhibitors, and the risk of tumor lysis syndrome (TLS) with venetoclax-based regimens, etc. The best frontline regimen for patients with CLL continues to evolve, and the optimal sequencing of therapies in later lines remains unclear. Treatment of Richter's transformation (RT) remains unsatisfactory and a major unmet clinical need. In this article, we update our last review of the topic ${ }^{1}$, covering the major and practice-changing therapeutic advances in CLL over the last 3 years with a focus on the BTK inhibitors and venetoclax. A comprehensive review on the treatment of CLL was recently published ${ }^{2}$.

\section{Update on ibrutinib monotherapy}

After ibrutinib's Food and Drug Administration (FDA) approval as monotherapy for both relapsed/refractory and treatment-naïve patients with CLL based on the RESONATE ${ }^{3}$ and RESONATE- $2^{4}$ phase 3 randomized controlled trials (RCTs), the results of several important phase 3 trials comparing ibrutinib-based regimens to chemoimmunotherapy (CIT) have been reported in the last 3 years, firmly establishing ibrutinib in the frontline setting for both younger and older patients. In the final analysis of RESONATE with a median follow-up of 65.3 months, median progression-free survival (PFS) remained significantly longer for patients randomized to ibrutinib versus ofatumumab (44.1 versus 8.1 months, $P<0.001)^{5}$. These results were virtually identical in the genomically high-risk subset of patients (deletion 17p [del17p], TP53 mutation [TP53 $\left.{ }^{m u t}\right]$, del11q, unmutated $I G H V$ ), who comprised $82 \%$ of the study population. The overall response rate (ORR) to ibrutinib was $91 \%$, with $11 \%$ of patients achieving complete response (CR) or CR with incomplete count recovery (CRi). Hypertension and atrial fibrillation occurred in $21 \%$ and $12 \%$ of patients, respectively (grade $\geq 3$ in $9 \%$ and $6 \%$ ), with $16 \%$ of patients discontinuing ibrutinib because of AEs. Both the PFS and overall survival (OS) benefits of ibrutinib over chlorambucil were sustained after a median follow-up time of 60 months in the RESONATE-2 trial $^{6}$. The 5-year PFS and OS estimates were $70 \%$ and $83 \%$ for ibrutinib and $12 \%$ and $68 \%$ for chlorambucil, respectively. The investigator-assessed ORR to ibrutinib was $92 \%$ with a CR rate of $30 \%$ in this frontline trial. In the context of ibrutinib monotherapy, use in the frontline setting is associated with a higher likelihood of CR, as is the lack of bulky lymphadenopathy $(\geq 5 \mathrm{~cm})^{7}$. While it remains unclear whether achievement of CR with ibrutinib impacts long-term outcomes, a study from the MD Anderson Cancer Center (MDACC) reported a statistically significant association between $\mathrm{CR}$ and $\mathrm{PFS}^{8}$. The rate of 2-year PFS was $85 \%$ in an investigator-initiated trial conducted at the National Institutes of Health (NIH) in 34 previously untreated CLL patients with TP53 alterations who received ibrutinib monotherapy; median time to progression (TTP) was 53 months .

\section{Ibrutinib versus CIT}

The results of two important US Intergroup phase 3 studies comparing ibrutinib-based regimens in the frontline setting against standard CIT regimens in both older and younger patients with CLL were recently published. The Alliance trial (A041202) randomized 547 older patients ( $\geq 65$ years of age) with previously untreated CLL to receive one of ibrutinib alone, ibrutinib plus rituximab, or bendamustine plus rituximab $(\mathrm{BR})^{10}$. At the time of publication, median PFS had not been reached in either of the ibrutinib-containing arms. Importantly, ibrutinib was continued until disease progression, while BR was administered for a standard 6 cycles. The estimated 2-year PFS rate was $74 \%$ for BR, $87 \%$ for ibrutinib alone, and $88 \%$ for ibrutinib/rituximab. PFS was not significantly different between the two ibrutinib-containing groups. No differences were apparent among the three arms in terms of OS at a median followup of 38 months. The rate of grade $\geq 3$ hematologic AEs was higher in the BR arm (61\%) than in the ibrutinib-containing arms $(\approx 40 \%)$, but that of grade $\geq 3$ non-hematologic AEs was higher in each ibrutinib-containing arm (74\%) than in the BR $\operatorname{arm}(63 \%)$.

The Eastern Cooperative Oncology Group (ECOG) 1912 trial randomized 529 treatment-naive patients with CLL $\leq 70$ years of age $2: 1$ to receive ibrutinib (until disease progression) plus rituximab (6 cycles) or 6 cycles of fludarabine, cyclophosphamide, and rituximab (FCR) ${ }^{11}$. Patients with del17p CLL were excluded from this trial given their known poor outcomes with CIT. After a median of 33.6 months of follow-up, this trial demonstrated both a PFS and an OS advantage for ibrutinib plus rituximab over FCR (3-year PFS, 89.4\% versus $72.9 \%$; 3-year OS, $98.8 \%$ versus $91.5 \%, P<0.001$ for both comparisons). Importantly, there was no difference in 3-year PFS ( $87.7 \%$ for ibrutinib/rituximab and $88 \%$ for FCR) between the two arms when considering only the $I G H V$-mutated patients, in line with the known excellent long-term outcomes with FCR in this subgroup ${ }^{12}$. An update of the ECOG trial with longer follow-up (median 45 months) was presented at the 2019 American Society of Hematology (ASH) annual meeting ${ }^{13}$. The rate of grade $\geq 3$ AEs was $70 \%$ in the ibrutinib/rituximab arm and $80 \%$ in the FCR arm $(P=0.013)$. A total of 95 patients discontinued ibrutinib (24\% owing to disease progression or death, $51 \%$ owing to AEs or complications, and $25 \%$ owing to withdrawal of consent or other reasons), after which the median time to disease progression or death was 23 months. Only an increased baseline Cumulative Illness Rating Scale (CIRS) score predicted discontinuation of ibrutinib for reasons other than disease progression or death. 


\section{Ibrutinib addition to CIT}

An interesting strategy being pursued at MDACC to optimize FCR for younger patients with $I G H V$-mutated CLL and no del17p/TP53 ${ }^{\text {mut }}$ is the combination of ibrutinib, fludarabine, cyclophosphamide, and obinutuzumab (iFCG), in which the chemotherapy is limited to 3 courses in an effort to reduce the risk of therapy-related myeloid neoplasms (t-MNs) and the duration of ibrutinib and obinutuzumab is determined through assessments of measurable residual disease (MRD) at different time points. Recently presented results from this study showed that the best ORR was 98\% (44 of 45 patients) and the rates of bone marrow MRD clearance were $87 \%$ after 3 cycles and $89 \%$ after 6 cycles $^{14}$. A total of 41 patients reached the 1-year time point and all discontinued therapy, being MRD negative in the bone marrow; no patient had experienced clinical relapse after a median follow-up of 22.7 months since ibrutinib discontinuation. There was one MRD recurrence and one patient developed therapy-related myelodysplastic syndrome at a median follow-up of 34.2 months.

Investigators at the Dana Farber Cancer Institute (DFCI) have studied ibrutinib (for up to 2 years) in combination with 6 cycles of FCR (iFCR) in unselected, younger ( $\leq 65$ years of age) patients with CLL: of 85 patients enrolled, 71 (84\%) achieved a best response of undetectable MRD in the bone marrow, while a third of patients achieved CR plus undetectable bone marrow MRD 2 months after the last cycle of $\mathrm{iFCR}^{15}$.

Although the addition of rituximab to ibrutinib does not extend PFS beyond that achieved with ibrutinib alone ${ }^{10,16}$, the same may not be true of obinutuzumab, a type II glycoengineered CD20 monoclonal antibody proven superior to rituximab in the pivotal German CLL11 trial ${ }^{17}$. Obinutuzumab possesses enhanced antibody-dependent cellular cytotoxicity (ADCC) compared to rituximab, a process that may, at least preclinically, be antagonized by ibrutinib via inhibition of interleukin-2-inducible T-cell kinase $(\text { ITK })^{18}$. While there has been no direct comparison of ibrutinib plus obinutuzumab against ibrutinib alone, the former regimen is now FDA approved for frontline therapy based on the industry-sponsored iLLUMINATE trial ${ }^{19}$. In this phase 3 RCT, 229 patients with previously untreated CLL aged $\geq 65$ years or younger than 65 with coexisting conditions were randomized 1:1 to receive 6 cycles of obinutuzumab and either continuous daily ibrutinib (until disease progression) or chlorambucil $(0.5 \mathrm{mg} / \mathrm{kg}$ on days 1 and 15 every 28 days for 6 cycles). After a median follow-up of 31.3 months, the median PFS in the ibrutinib/obinutuzumab group had not been reached, while that in the chlorambucil/obinutuzumab group was 19 months $(P<0.0001)$. The estimated 30-month PFS rates were $79 \%$ and $31 \%$, respectively. Serious AEs occurred in $58 \%$ of patients in the ibrutinib/obinutuzumab group and in $35 \%$ of patients receiving chlorambucil/obinutuzumab.

\section{Ibrutinib toxicities and the need for more selective BTK inhibitors}

Overall, ibrutinib is well tolerated; in an integrated safety analysis of ibrutinib-treated (for up to 43 months) patients from
RESONATE $(\mathrm{n}=195)$ and RESONATE-2 $(\mathrm{n}=135)$, the most frequent AEs were diarrhea (52\%, grade 3 in 5\%) and fatigue $(36 \% \text {, grade } 3 \text { in } 3 \%)^{20}$. The most common grade 3/4 AEs were neutropenia $(18 \%)$ and pneumonia $(12 \%)$. The prevalence of hypertension increased over time. Dose reductions and discontinuation due to AEs occurred in $13 \%$ and $11 \%$ of patients, respectively. In a "real world" analysis of 616 patients with a median follow-up of 17 months, an estimated $41 \%$ discontinued ibrutinib, mostly because of toxicities, after a median of 7 months $^{21}$. Atrial fibrillation is, of course, a well-established risk associated with ibrutinib therapy ${ }^{22}$. Pooled data on 1,505 CLL and mantle cell lymphoma (MCL) patients participating in 4 RCTs of ibrutinib showed an estimated cumulative incidence of atrial fibrillation of $13.8 \%$; over $85 \%$ of patients with atrial fibrillation were able to remain on ibrutinib, and over half received common anticoagulant/antiplatelet medications ${ }^{23}$. In contrast, the risk of ibrutinib-related atrial fibrillation was as high as $38 \%$ at 2 years in one "real world" study ${ }^{24}$. Investigators at the Ohio State University (OSU) reported a cumulative incidence of $5.9 \%, 7.5 \%$, and $10.3 \%$ at $0.5,1$, and 2 years, respectively, in a study of 582 ibrutinib-treated patients with a median follow-up of 32 months $^{25}$. Another serious concern with ibrutinib has been the risk of ventricular arrhythmias ${ }^{26,27}$. Indeed, in the three-arm phase 3 Alliance RCT, it was speculated that these might have precipitated a number of otherwise unexplained or unwitnessed deaths on the ibrutinib-containing $\operatorname{arms}^{10}$. In an earlier report, 10 cases of sudden death or cardiac arrest were identified in published clinical trials of ibrutinib amongst approximately 1,000 total participants ${ }^{26}$. In the OSU experience, $78.3 \%$ of 562 consecutive patients receiving ibrutinib for B-cell malignancies developed new (71.6\%) or worsened hypertension, associated with an increased risk of major adverse cardiovascular events, over a median of 30 months $^{28}$. Of note, the cardiovascular effects of ibrutinib have been attributed, at least in part, to off-target inhibition of other kinases ${ }^{29,30}$, suggesting an advantage for more selective inhibitors of BTK in this regard. This is less clear with respect to the bleeding diathesis induced by BTK inhibitors, with conflicting results in studies comparing the effects of ibrutinib and newer, more selective BTK inhibitors on platelet function ${ }^{31-33}$.

The group at OSU also reported 23 cases of opportunistic infection over 1,225 patient-years of ibrutinib exposure in 566 patients with B-cell malignancies, i.e. an incidence rate of 1.9 per 100 person-years ${ }^{34}$. The majority of these were invasive fungal infections, particularly invasive aspergillosis, as has been reported by others ${ }^{35}$. Preclinically, it has been shown that BTK blockade by ibrutinib impairs phagocytosis of Aspergillus fumigatus by macrophages ${ }^{36}$ and that neutrophils in patients receiving ibrutinib also develop multiple functional defects that impair their response against this pathogen ${ }^{37}$.

\section{Second-generation BTK inhibitors}

Similar to ibrutinib, acalabrutinib and zanubrutinib are irreversible inhibitors of BTK that bind covalently to the Cys 481 residue. Indeed, point mutations at this binding site, e.g. C481S, have been shown to confer resistance to acalabrutinib ${ }^{38}$, 
just as they do to ibrutinib ${ }^{39}$. However, these second-generation BTK inhibitors are more selective for BTK than ibrutinib, which might mean improved safety owing to reduced off-target toxicity and could potentially provide more sustained BTK occupancy due to twice daily dosing. Acalabrutinib was approved by the FDA for the treatment of CLL based on the results of 2 phase 3 RCTs, ELEVATE-TN and ASCEND, conducted in the treatment-naïve and relapsed/refractory settings, respectively. The ELEVATE-TN trial compared acalabrutinib alone, acalabrutinib plus obinutuzumab, and chlorambucil plus obinutuzumab in 535 previously untreated patients with CLL $\geq 65$ years of age or younger than 65 but with coexisting conditions ${ }^{40}$. Acalabrutinib's lack of inhibition of ITK makes it, at least in theory, a better partner for CD20 monoclonal antibodies than ibrutinib and, in a small, single-arm trial conducted at OSU, acalabrutinib plus obinutuzumab produced ORRs of 95\% (32\% CRs) and 92\% (8\% CRs) in 19 treatment-naïve and 26 relapsed/ refractory patients with CLL, respectively ${ }^{41}$. The 3-year PFS rates were $94 \%$ and $88 \%$, respectively. In ELEVATE-TN, acalabrutinib was continued in both arms until disease progression or unacceptable toxicity, while chlorambucil/obinutuzumab was administered for a standard 6 cycles. At a median follow-up of 28.3 months, median PFS had not been reached in either acalabrutinib arm and was 22.6 months for chlorambucil/obinutuzumab ( $P<0.0001$ for both comparisons). The 2-year PFS rates were $93 \%$ for acalabrutinib/obinutuzumab, $87 \%$ for acalabrutinib alone, and $47 \%$ for chlorambucil/obinutuzumab. While the trial was not powered for this comparison, an exploratory post hoc analysis showed that acalabrutinib plus obinutuzumab was superior in terms of PFS to acalabrutinib monotherapy. The estimated 2-year OS rates, however, were not significantly different. The ORRs in the acalabrutinib plus obinutuzumab, acalabrutinib monotherapy, and chlorambucil plus obinutuzumab arms were $94 \%, 86 \%$, and $79 \%$, respectively. The rates of serious AEs were $38.8 \%, 31.8 \%$, and $21.9 \%$, respectively, and those of grade $\geq 3$ AEs were $70.2 \%, 49.7 \%$, and $69.8 \%$, respectively. Headache, diarrhea, fatigue, contusion, arthralgia, cough, upper respiratory infection (URI), nausea, dizziness, and neutropenia were all common $(\geq 10 \%)$ in the acalabrutinib arms, more so in the acalabrutinib/obinutuzumab arm, although grade $\geq 3$ neutropenia occurred most frequently in the chlorambucil/ obinutuzumab arm. Atrial fibrillation occurred in $3.4 \%$ of patients receiving acalabrutinib in combination with obinutuzumab and in $3.9 \%$ of those receiving acalabrutinib alone.

Final results from the ASCEND study ${ }^{42}$, which compared acalabrutinib monotherapy $1: 1$ to physician's choice of either idelalisib plus rituximab (IdR) or BR in 310 patients with relapsed/ refractory CLL or small lymphocytic lymphoma (SLL), were recently presented ${ }^{43}$. At a median follow-up of 22 months, median PFS had not been reached for the acalabrutinib arm and was 16.8 months for the BR and IdR arms combined $(P<0.0001)$. Overall response rates (including partial response [PR] with lymphocytosis, $\mathrm{PR}_{\mathrm{L}}$ ) also favored acalabrutinib $(92 \%$, versus $88 \%$ for $\mathrm{IdR} / \mathrm{BR}$ ). The 18 -month $\mathrm{OS}$ rate was $88 \%$ for both acalabrutinib and IdR/BR, but $51 \%$ of the IdR/BR patients had crossed over to receive acalabrutinib upon disease progression. AEs led to drug discontinuation in $16 \%$ of acalabrutinib, $56 \%$ of IdR, and $17 \%$ of BR patients. The rates of atrial fibrillation, major hemorrhage, and grade $\geq 3$ infections were $6 \%$ and $3 \%, 3 \%$ and $3 \%$, and $20 \%$ and $25 \%$ for the acalabrutinib and IdR/BR groups, respectively. Acalabrutinib, $100 \mathrm{mg}$ twice daily, yielded an ORR of $94 \%$ in a phase $1 \mathrm{~b} / 2$ study in 134 patients with relapsed/refractory CLL/SLL and a median of 2 prior therapies ${ }^{44}$. The ORR was not significantly affected by adverse genomic features. The estimated 45-month PFS rate was $62 \%$ (the median PFS had not been reached for the overall population but was 36 and 33 months for patients with del17p and complex karyotype, respectively). Diarrhea (52\%) and headache $(51 \%)$ were common; atrial fibrillation and major bleeding occurred in $7 \%$ and $5 \%$ of patients, respectively. Grade $\geq 3$ neutropenia, pneumonia, hypertension, anemia, and diarrhea were observed in $5-14 \%$ of patients. Given its improved safety profile, acalabrutinib has been studied specifically in patients with CLL $(n=33)$ intolerant to ibrutinib ${ }^{45}$. The most common treatment-emergent AEs on acalabrutinib were diarrhea (58\%), headache (39\%), and cough (33\%). Grade 3/4 neutropenia and thrombocytopenia occurred in $12 \%$ and $9 \%$, respectively, although the overall rate of grade 3/4 AEs was $58 \%$. A total of $72 \%$ of ibrutinib-related AEs did not recur on acalabrutinib, and $13 \%$ recurred at a lower grade. After a median follow-up of 19 months, 23 of the 33 patients remained on acalabrutinib. The ORR was $76 \%$, and the median PFS and duration of response (DOR) to acalabrutinib had not been reached.

Zanubrutinib is another potent, second-generation BTK inhibitor with improved selectivity over ibrutinib that has been approved by the FDA for patients with MCL who have received $\geq 1$ prior therapy. Administered twice daily like acalabrutinib, zanubrutinib has not been approved yet for patients with CLL but has demonstrated high efficacy with low toxicity in early phase trials ${ }^{46}$. Clinical trial results to date with zanubrutinib in patients with CLL/SLL are summarized in Table 1. A randomized, phase 3 trial (ALPINE) will compare zanubrutinib to ibrutinib in the relapsed/refractory setting ${ }^{47}$.

As alluded to above, acquired mutations, e.g. C481S, in BTK (and gain-of-function mutations in phospholipase $\mathrm{C}$ gamma 2 [PLCG2] immediately downstream of BTK in the BCR signaling cascade) underlie most cases of resistance to irreversible BTK inhibitors, and their acquisition has been shown to precede clinical relapse or progression ${ }^{48}$. These observations have led to the development of third-generation BTK inhibitors.

\section{Third-generation BTK inhibitors}

Third-generation BTK inhibitors were designed to circumvent the development of resistance to first- and second-generation BTK inhibitors due to point mutations at the C481 residue. This class of compounds, e.g. LOXO-305 $5^{49}$, SNS-062 (vecabrutinib) $^{50}$, and ARQ-531 $1^{51}$, binds to an allosteric site of the kinase. These agents are in early clinical development in 
Table 1. Clinical trial results with zanubrutinib monotherapy in patients with CLL/SLL.

\begin{tabular}{|c|c|c|c|c|c|}
\hline Phase & Eligibility & Patients & Efficacy & Safety & Reference \\
\hline $1(\mathrm{FIH})$ & $\begin{array}{l}\text { R/R B-cell } \\
\text { malignancies in dose } \\
\text { escalation portion } \\
\text { (part 1); disease- } \\
\text { specific cohorts in } \\
\text { expansion portion } \\
\text { (part 2) }\end{array}$ & $\begin{array}{l}\mathrm{n}=94 ; 22 \mathrm{TN}, 72 \mathrm{R} / \mathrm{R} ; \\
\text { median } 2 \text { prior therapies. } \\
\text { Del17p/TP53mut } 19.1 \% ; \\
\text { del11q, } 23.3 \% ; \text { unmutated } \\
\text { IGHV, 66.7\%; LAD }>10 \mathrm{~cm} \text {, } \\
5.3 \%\end{array}$ & $\begin{array}{l}\text { In } 78 \text { evaluable } \\
\text { pts, ORR } 96.2 \% \\
(2.6 \% \mathrm{CR}+80.8 \% \\
\left.\mathrm{PR}+12.8 \% \mathrm{PR}_{\mathrm{L}}\right) \\
\text { estimated } 12 \mathrm{~m} \text { PFS } \\
100 \% \text { at median } \mathrm{f} / \mathrm{u} \\
13.7 \mathrm{~m} \text {, median PFS } \\
\text { not reached }\end{array}$ & $\begin{array}{l}\text { No DLT observed; } 160 \text { mg } \\
\text { bid selected as RP2D based } \\
\text { on sustained >95\% BTK } \\
\text { occupancy in LN. No deaths. } \\
\text { Gr } 3 / 4 \text { anemia, neutropenia, } \\
\text { HTN, pneumonia in >1 } \\
\text { patient }\end{array}$ & 46 \\
\hline $\begin{array}{l}1 / 2 \text { (update of } \\
\text { above study } \\
\text { with median } \\
\text { f/u } 29.5 \mathrm{~m} \text { ) }\end{array}$ & As above & $\begin{array}{l}\mathrm{n}=123 ; 22 \mathrm{TN}, 101 \mathrm{R} / \mathrm{R} ; \\
\text { median } 2 \text { prior therapies. } \\
\text { Del17p, } 16.2 \% \text {; TP53 } 3^{\text {mut }} \\
\text { 31\%; del11q, } 23.5 \% \text {; } \\
\text { unmutated } / G H V, 68.3 \% \text {; } \\
\text { LAD >5 cm, 38.2\% }\end{array}$ & $\begin{array}{l}\mathrm{n}=123 ; \text { ORR } 100 \% \\
(22.7 \% \mathrm{CR}+77.3 \% \\
\mathrm{PR}) \text { in TN pts, } 95 \% \\
(13.9 \% \mathrm{CR}+72.3 \% \\
\left.\mathrm{PR}+7.9 \% \mathrm{PR}_{\mathrm{L}}\right) \text { in } \\
\text { R/R pts. Median PFS } \\
32.2 \mathrm{~m} \text { for TN pts, } \\
23.1 \mathrm{~m} \text { for R/R pts }\end{array}$ & $\begin{array}{l}n=123 ; \mathrm{gr} \geq 3 \text { AEs in } 61.8 \% \text {, } \\
\text { SAEs in } 47.2 \% \text {, AEs led to } \\
\text { D/C in } 4.1 \% \text {. Most common } \\
\text { AEs (>20\%): contusion, URI, } \\
\text { diarrhea, cough, headache, } \\
\text { fatigue. Gr } \geq 3 \text { a fib: } 1.6 \%\end{array}$ & 52 \\
\hline 3 (SEQUOIA) & $\begin{array}{l}\text { Multiple cohorts } \\
\text { (TN); cohort 1, Z vs. } \\
\text { BR in non-del17p; } \\
\text { cohort 2, Z alone in } \\
\text { del17p; cohort } 3, \mathrm{Z}+ \\
\text { V in del17p }\end{array}$ & $\begin{array}{l}\text { Cohort } 2 \text { (Arm C) only: } \\
\mathrm{n}=109 ; \text { all with del17p, } \\
\mathrm{TN} \text {; del11q in } 33.9 \%, \\
\text { unmutated } / \mathrm{GHV} \text { in } 61.5 \% \text {, } \\
\beta 2 \mathrm{~m}>3.5 \mathrm{~g} / \mathrm{dL} \text { in } 78.6 \% \\
\mathrm{LAD} \geq 5 \mathrm{~cm} \text { in } 38.5 \% \\
\text { median f/u } 18.2 \mathrm{~m}\end{array}$ & $\begin{array}{l}\mathrm{n}=109 ; \text { ORR } 94.5 \% \\
(3.7 \% \mathrm{CR} / \mathrm{CRi}+ \\
87.2 \% \mathrm{PR}+3.7 \% \\
\left.\mathrm{PR}_{\mathrm{L}}\right) ; \text { median PFS, } \\
\text { DOR, and OS not } \\
\text { reached }\end{array}$ & $\begin{array}{l}\text { Most common AEs } \\
\text { (>10\%): contusion, URI, } \\
\text { neutropenia, diarrhea, } \\
\text { nausea, constipation, rash, } \\
\text { back pain, cough, arthralgia, } \\
\text { fatigue. A fib or flutter: } 2.8 \% \text {. } \\
\text { AEs led to D/C in } 3.7 \% \text {. } \\
\text { Gr } \geq 3 \text { AEs in }>2 \% \text { of pts: } \\
\text { neutropenia, pneumonia }\end{array}$ & 53 \\
\hline
\end{tabular}

Abbreviations: AE, adverse event; a fib, atrial fibrillation; BR, bendamustine plus rituximab; BTK, Bruton's tyrosine kinase; CLL, chronic lymphocytic leukemia; $\mathrm{CR} / \mathrm{CRi}$, complete response with or without count recovery; D/C, discontinuation; DLT, dose-limiting toxicity; DOR, duration of response; FIH, first in human; f/u, follow-up; gr, grade; HTN, hypertension; LAD, Iymphadenopathy; LN, Iymph node; m, month; ORR, overall response rate; OS, overall survival; PFS, progression-free survival; PR, partial response; PR, partial response with lymphocytosis; pts, patients; RP2D, recommended phase 2 dose; R/R, relapsed/ refractory; SAE, serious adverse event; SLL, small lymphocytic lymphoma; TN, treatment-naive; tox, toxicity; URI, upper respiratory infection; V, venetoclax; Z, zanubrutinib.

patients with relapsed/refractory CLL and MCL, primarily those who have failed therapy with ibrutinib. Results on 94 patients with CLL/SLL (median 4 prior therapies, including a BTK inhibitor in $84 \%$, a PI3K inhibitor in $21 \%$, and venetoclax in $31 \%$ ) enrolled in the phase $1 / 2$ BRUIN trial of LOXO-305 were recently presented ${ }^{49}$. Del17p was present in $21 \%$, TP $^{\text {mut }}$ in $30 \%$, and unmutated $I G H V$ in $84 \%$. The only treatment-emergent AEs observed in $\geq 10 \%$ of patients were fatigue $(16 \%)$ and diarrhea $(15 \%)$. The recommended phase 2 dose was $200 \mathrm{mg}$ daily. A total of 65 patients were evaluable for efficacy; the ORR was $57 \%$ after a median follow-up of 3 months (77\% among 26 patients with at least 6 months of follow-up). Responses were not influenced by the presence or absence of a pre-treatment BTK C481 mutation, reason for prior BTK inhibitor discontinuation (i.e. resistance or intolerance), or other classes of prior therapy received.

\section{Venetoclax}

The BH3-mimetic venetoclax has quickly gone from its first FDA approval in 2016 for patients with relapsed, del17p $\mathrm{CLL}^{54}$ to full approval (in combination with CD20 monoclonal antibodies) for all CLL patients. The issue of tumor lysis syndrome (TLS) has been successfully mitigated by the implementation of a dose ramp-up, in which the venetoclax dose is raised in a step-wise fashion every week from $20 \mathrm{mg}$ to $50 \mathrm{mg}$ to $100 \mathrm{mg}$ to $200 \mathrm{mg}$ to the target dose of $400 \mathrm{mg}$ daily ${ }^{55}$. Importantly, venetoclax is able to eradicate blood and marrow MRD even as a single agent, an effect not seen with ibrutinib.

In an update of the original pivotal trial in 158 patients with (mostly) relapsed/refractory CLL with del17p and a median of 2 prior therapies, $71 \%$ of whom had $T P 53^{\text {mut }}$ and $48 \%$ of whom had nodes $\geq 5 \mathrm{~cm}$, a blood MRD clearance rate of $30 \%$ was reported $^{56}$. Median time on venetoclax was 23.1 months. The investigator-assessed ORR was $77 \%$ and the estimated 2-year PFS was $54 \%(63 \%$ and $50 \%$, respectively, in the 16 patients who had received prior kinase inhibitors).

Pooled data from several early phase studies of venetoclax in patients with relapsed/refractory CLL were analyzed to comprehensively characterize the safety profile of venetoclax monotherapy as well as identify factors predictive of efficacy. Among 350 patients who had received a median of 3 prior therapies (including ibrutinib or idelalisib in $42 \%$ ), the median 
duration of exposure to venetoclax was 16 months ${ }^{57}$. The most common AEs were diarrhea, neutropenia, nausea (frequency for each $\approx 40 \%$ ), anemia, fatigue, and URI (each in the $25-30 \%$ range). The most common grade $3 / 4$ AEs were cytopenias, particularly neutropenia (neutrophils are dependent upon the pro-survival function of BCL-2). Serious infections occurred in $15 \%$. In a similar analysis of efficacy $(n=436)$, the ORR was $75 \%$, including a $22 \% \mathrm{CR} / \mathrm{CRi}$ rate $^{58}$. Undetectable MRD in the blood and marrow, respectively, was achieved by $27 \%$ and $16 \%$ of the patients. The estimated PFS was 30.2 months. For those who achieved CR/CRi, the 3-year PFS estimate was $83 \%$. Achievement of CR/CRi or undetectable MRD predicted for longer DOR, while bulky lymphadenopathy $(\geq 5 \mathrm{~cm})$ and refractoriness to prior BCR inhibitor therapy were significantly associated with lower $\mathrm{CR}$ rates and shorter DOR. Del17p and/or $T P 53^{\text {mut }}$ and $N O T C H 1^{\text {mut }}$ were consistently associated with shorter DOR, but not ORR. Fewer prior therapies predicted for higher CR rates, but not DOR. Of practical importance, the efficacy of single agent venetoclax after failure/discontinuation of BCR pathway inhibitors has been specifically studied; these data are summarized in Table 2.

\section{Venetoclax combinations with CD20 monoclonal antibodies: finite duration regimens \\ Venetoclax with rituximab}

MURANO was a phase 3 RCT that compared the combination of venetoclax plus rituximab (Ven-R, venetoclax for 2 years and rituximab for 6 cycles) to 6 cycles of BR in 389 patients with relapsed/refractory CLL (1-3 prior therapies $)^{59}$. Del17p was detected in $26.9 \%$ of 342 patients tested, TP53 ${ }^{\text {mut }}$ in
$26.3 \%$ of 376 tested, and unmutated $I G H V$ in $68.3 \%$ of 360 patients tested. After a median follow-up of 23.8 months, the 2-year (investigator-assessed, verified by independent review) PFS rate was $84.9 \%$ for Ven-R and $36.3 \%$ for BR, findings that led to the FDA approval of the Ven-R regimen for patients with relapsed/refractory CLL. The 2-year PFS rates for Ven-R were very similar in patients with and without del17p $(81.5 \%$ and $85.9 \%$, respectively), while those for BR were $27.8 \%$ and $41 \%$, respectively. The ORR and $\mathrm{CR} / \mathrm{CRi}$ rates were $92.3 \%$ and $8.2 \%$, respectively, in the Ven-R group, and $72.3 \%$ and $3.6 \%$ in the BR group. OS at 2 years favored Ven-R as well $(91.9 \%$ versus $86.6 \%$ with $\mathrm{BR}$ ). Rates of MRD clearance in both blood (available in 94.1\%) and marrow (available in 29.6\%) were much higher in the Ven-R group $(62.4 \%$ at 9 months and $83.5 \%$ at any time in the peripheral blood) than in the BR group (13.3\% at 9 months and $23.1 \%$ at any time), and MRD clearance rates at the 9-month time point predicted subsequent PFS. Grade 3/4 neutropenia occurred more frequently in the Ven-R group, but the rates of grade 3/4 febrile neutropenia $(\mathrm{FN})$ and infections were higher with BR. Grade 3/4 TLS occurred in $3.1 \%$ of patients in the Ven-R group.

In the most recent update of this trial (median follow-up, 59.2 months), the median PFS was 53.6 months for Ven-R and 17 months for BR, and the 5-year OS estimates were $82.1 \%$ and $62.2 \%$ for Ven-R and BR, respectively ${ }^{60}$. For patients completing the 2 years of venetoclax, the PFS estimate 36 months after the end of treatment (EOT) was $\approx 51.1 . \%$. For Ven-R patients who reached EOT without disease progression, undetectable MRD at EOT (83/118) predicted improved OS (3-year

Table 2. Efficacy of venetoclax monotherapy after ibrutinib, idelalisib, or both.

\begin{tabular}{|c|c|c|c|c|}
\hline Study design & Patients & Efficacy & Safety & Reference \\
\hline $\begin{array}{l}\text { Open-label, non- } \\
\text { randomized, multi- } \\
\text { center, phase } 2 \\
\text { trial (prior ibrutinib } \\
\text { cohort) }\end{array}$ & $\begin{array}{l}91 \text { pts with R/R CLL who } \\
\text { had received ibr as their } \\
\text { last BCRi; median f/u } 14 \mathrm{~m} \text {. } \\
\text { lbr D/Ced due to disease } \\
\text { progression in } 55 \% \text { and AEs } \\
\text { in } 33 \% \text {; } 68 \% \text { refractory to ibr, } \\
31 \% \text { relapsed on or after ibr } \\
\text { D/C }\end{array}$ & $\begin{array}{l}\text { ORR } 65 \% \text { ( } 9 \% \text { CR/CRi } \\
+3 \% \text { nPR + 52\% PR). } \\
\text { Median PFS } 24.7 \text { m, } \\
\text { median OS not reached. } \\
\text { Estimated } 12-m \text { PFS, } 75 \% \text {; } \\
\text { estimated } 12-m \text { OS, } 91 \%\end{array}$ & $\begin{array}{l}\text { Most common treatment-emergent } \\
\text { gr } 3 / 4 \text { AEs: neutropenia }(51 \%) \text {, } \\
\text { thrombocytopenia (29\%), anemia } \\
(29 \%) \text {, leukopenia (19\%), lymphopenia } \\
(15 \%)\end{array}$ & 61 \\
\hline $\begin{array}{l}\text { As above (prior } \\
\text { idelalisib cohort) }\end{array}$ & $\begin{array}{l}36 \text { pts with } R / R \text { CLL who } \\
\text { had received ide as their last } \\
\text { BCRi; median duration of } \\
\text { prior ide } 9 \mathrm{~m} \text {; reason for ide } \\
\mathrm{D} / \mathrm{C} \text { : tox with subsequent } \mathrm{PD} \\
\text { in } 61 \% \text { and PD on ide in } 36 \% \text {; } \\
\text { median } \mathrm{f} / \mathrm{u} 14 \mathrm{~m}\end{array}$ & $\begin{array}{l}\text { ORR } 67 \% \text { ( } 8 \% \text { CR/CRi } \\
+58 \% \text { PR). Median PFS } \\
\text { and OS not reached. } \\
\text { Estimated } 12-\text {-m PFS, } 79 \% \text {; } \\
\text { estimated } 12-\text { m OS, } 94 \%\end{array}$ & $\begin{array}{l}\text { Most common gr } 3 / 4 \text { AEs: neutropenia } \\
(50 \%) \text {, thrombocytopenia (25\%), } \\
\text { anemia ( } 17 \%) \text {; all grades: neutropenia } \\
(56 \%) \text {, diarrhea ( } 42 \%) \text {, URI }(39 \%) \text {, } \\
\text { thrombocytopenia }(36 \%) \text {, nausea } \\
(31 \%) \text {, fatigue ( } 28 \%) \text {, cough }(22 \%) \text {, } \\
\text { rash }(22 \%) \text {, anemia (22\%) }\end{array}$ & 62 \\
\hline $\begin{array}{l}\text { As above (post hoc } \\
\text { analysis of pts who } \\
\text { had received }>1 \\
\text { prior BCRi) }\end{array}$ & $\begin{array}{l}28 \text { pts with R/R CLL who had } \\
\text { received >1 BCRi (ibr and ide } \\
\text { in } 86 \% \text { ); median } \mathrm{f} / \mathrm{u} 11.8 \mathrm{~m}\end{array}$ & $\begin{array}{l}\text { ORR } 43 \% \text { ( } 4 \% \text { CR }+39 \% \\
\text { PR); median PFS } 16.4 \mathrm{~m} \text {. } \\
\text { Estimated } 12-\mathrm{m} \text { PFS, } 58 \% \text {; } \\
\text { estimated } 12-\mathrm{m} \text { OS, } 89 \%\end{array}$ & $\begin{array}{l}\text { Common AEs: gr } 1 / 2 \mathrm{Gl} \text { tox and gr } 3 / 4 \\
\text { cytopenias }\end{array}$ & 63 \\
\hline
\end{tabular}

Abbreviations: AE, adverse event; BCRi, B-cell receptor pathway inhibitor; CLL, chronic lymphocytic leukemia; CR/CRi, complete response with or without count recovery; D/C, discontinuation; f/u, follow-up; GI, gastrointestinal; gr, grade; ibr, ibrutinib; ide, idelalisib; m, month; nPR, nodular partial response; ORR, overall response rate; OS, overall survival; PFS, progression-free survival; PR, partial response; pts, patients; R/R, relapsed/refractory; tox, toxicity; URI, upper respiratory infection. 
post-EOT survival estimate $95.3 \%$ versus $85 \%$ for those [35/118] with detectable MRD at EOT). Of the 83 Ven-R patients with undetectable MRD at EOT, 32 remained MRD negative at 5 years, 4 had disease progression without confirmation of MRD conversion, and 47 developed MRD conversion a median of 19.4 months after EOT; of these 47, 19 subsequently developed progressive disease after another 25.2 months (median). Baseline risk factors associated with increased risk of MRD conversion among patients with undetectable MRD at EOT were del17p, complex karyotype, and unmutated $I G H V$. No new safety signals were identified. Importantly, peripheral blood MRD assessment has been shown to be a good surrogate for bone marrow MRD assessment in the context of venetoclax therapy in relapsed/refractory CLL, correlating equally well with long-term outcomes ${ }^{64}$. Furthermore, no new attainment of MRD-negative status was observed after 24 months; concurrent rituximab hastened the attainment of undetectable MRD, while complex karyotype was associated with lower rates of undetectable MRD at 12 months. Of interest, a retrospective, realworld analysis $(n=321)$ found no differences in terms of ORR, PFS, and OS between heavily pre-treated CLL patients receiving venetoclax monotherapy and those receiving venetoclax plus an anti-CD20 monoclonal antibody after a median follow-up of 13.4 months $^{65}$.

\section{Venetoclax with obinutuzumab}

In a phase $1 \mathrm{~b}$ study in 32 patients with previously untreated CLL and 50 with relapsed/refractory CLL, venetoclax plus obinutuzumab (Ven-G), administered for 6 cycles followed by venetoclax to complete 1 year (for treatment-naïve patients) or until disease progression (in relapsed/refractory patients), yielded ORRs of $95 \%(37 \% \mathrm{CR} / \mathrm{CRi})$ and $100 \%(78 \% \mathrm{CR} / \mathrm{CRi})$ in the relapsed/refractory and frontline cohorts, respectively ${ }^{66}$. MRD was undetectable in the peripheral blood $\geq 3$ months after the last obinutuzumab dose in $64 \%$ of the relapsed/refractory patients and $91 \%$ of the previously untreated patients.

The pivotal German CLL14 phase 3 RCT that led to the approval of Ven-G in the frontline setting compared this regimen $1: 1$ to the combination of chlorambucil and obinutuzumab in 432 treatment-naïve patients with CLL and a CIRS score $>6$ or a creatinine clearance $<70 \mathrm{~mL} /$ minute $^{67}$. The median age was $72,13.8 \%$ of the patients had TP53 $3^{\text {mut }}$, deletion or both, and $59.8 \%$ had unmutated IGHV. Obinutuzumab was administered for 6 cycles, while both venetoclax and chlorambucil $(0.5 \mathrm{mg} / \mathrm{kg}$ on days 1 and 15 of each 28 -day cycle) were administered for 12 cycles. Venetoclax was initiated on day 22 of cycle 1 in order to mitigate TLS risk. No crossover was permitted. After a median follow-up of 28.1 months, the estimated 2-year PFS rate was $88.2 \%$ in the Ven-G group and $64.1 \%$ in the chlorambucil/obinutuzumab group, a statistically significant benefit observed across pre-specified subgroups. Both the ORR and the CR rate were significantly higher in the Ven-G arm (ORR $84.7 \%$ versus $71.3 \%$ and CR $49.5 \%$ versus $23.1 \%$, $P<0.001$ for both comparisons). OS was not significantly different between the groups (median not reached in either group).
MRD clearance in the peripheral blood $(75.5 \%$ versus $35.2 \%$, $P<0.001)$ and bone marrow $(56.9 \%$ versus $17.1 \%, P<0.001)$ 3 months after therapy completion was also significantly better with Ven-G than with chlorambucil/obinutuzumab. In both arms, undetectable MRD in the peripheral blood at EOT correlated with favorable 24-month PFS rates in landmark analyses ${ }^{68}$. Most AEs occurred at similar frequencies in the two treatment arms. Neutropenia was the most common grade 3/4 AE, while grade $3 / 4 \mathrm{FN}$ occurred in $5.2 \%$ (all grades, $17.5 \%$ ) and $3.7 \%$ (all grades, 15\%) of the Ven-G and chlorambucil/obinutuzumab patients, respectively. No cases of clinical TLS ${ }^{69}$ were observed in either arm. A total of $56 \%$ of Ven-G patients with undetectable MRD at EOT had already achieved this after the combination phase of treatment, while in $25 \%$, the MRD response deepened during the 6 cycles of venetoclax monotherapy following the combination phase ${ }^{70}$. In a landmark analysis of PFS after EOT, Ven-G patients with MRD levels $\leq 10^{-5}$ had a 2 -year PFS rate of $\approx 93 \%$, while those with MRD levels $>10^{-2}$ had a 2-year PFS rate of $\approx 37 \%$. After a median follow-up of 39.6 months (all patients off treatment for at least 24 months), median PFS had not been reached in the Ven-G group versus 35.6 months in the chlorambucil/obinutuzumab group ${ }^{71}$.

\section{Ibrutinib plus venetoclax}

The combination of ibrutinib with venetoclax is a logical one given preclinical evidence of synergism ${ }^{72,73}$, the different disease compartments in which each drug appears most active (lymph nodes for ibrutinib, blood and marrow for venetoclax), and their high clinical efficacy as monotherapy. A number of clinical trials have evaluated this combination in both newly diagnosed and relapsed/refractory CLL.

In the MDACC phase 2 trial in 80 previously untreated highrisk/older patients, 75 of whom received the combination, venetoclax was introduced after 12 weeks ( 3 cycles) of ibrutinib monotherapy and administered for 24 cycles, following which ibrutinib could continue depending on bone marrow MRD status at the end of combination treatment ${ }^{74}$. After 12 cycles of combination therapy, $88 \%$ of patients had achieved CR/CRi, and $61 \%$ had undetectable bone marrow MRD. Responses improved and deepened with time and were seen independent of $I G H V$ mutation status, fluorescence in situ hybridization (FISH) category, and TP53/NOTCH1/SF3B1 mutation status. Atrial fibrillation developed in 12 patients (15\%) and was the most common reason for dose reduction of ibrutinib. FN occurred in four patients; neutropenia was the most common reason for dose reduction of venetoclax. In the most recent update (median follow-up, 33.8 months) of this trial, the rate of undetectable bone marrow MRD after 24 cycles of combination therapy by intention-to-treat (ITT) analysis was 66\%, and that at any time point was $75 \%^{75}$. A total of two patients developed RT; no patient had progression of their CLL. Of 24 patients who had detectable bone marrow MRD after 12 cycles of combination therapy, 12 achieved undetectable MRD in the bone marrow by the end of cycle 24. Based on this observation, the study has been amended to allow a further 12 cycles of 
combination therapy in patients with detectable bone marrow MRD at the end of cycle 24 .

The "MRD cohort" of the industry-sponsored, CAPTIVATE phase 2 study $(n=164)$ was very similarly designed, with MRD status evaluated in the peripheral blood after 6, 9, and 12 cycles and in the bone marrow after 12 cycles of combination ibrutinib and venetoclax (following a 3-cycle ibrutinib lead-in $)^{76}$. The median age was 58 , and the proportions of patients with del17p, del11q, del17p or TP53 $3^{\text {mut }}$, complex karyotype, and unmutated $I G H V$ were $16 \%, 17 \%, 20 \%, 19 \%$, and $60 \%$, respectively. A total of 86 patients achieved confirmed undetectable MRD serially over $\geq 3$ cycles, in both blood and marrow, after 12 cycles of combination therapy, and were randomized 1:1 to receive placebo or ibrutinib monotherapy; 1-year disease-free survival (DFS) did not differ significantly between these arms. A total of 63 patients did not achieve undetectable MRD as defined above and were randomized to continue ibrutinib plus venetoclax or ibrutinib alone. Rates of undetectable MRD in the blood and marrow improved in these patients. Rates of 30-month PFS were $>95 \%$ across all four arms.

A total of 80 patients were also enrolled to the relapsed/ refractory cohort of the MDACC trial $^{77}$. The median follow-up was 27 months when last presented, and 74 patients received combination treatment. By ITT analysis, the rates of undetectable bone marrow MRD after 12 cycles of combination therapy and at any time point (best response) were $40 \%$ and $56 \%$, respectively. When considering evaluable patients only, this rate was $47 \%$ after 12 cycles and 68\% after 24 cycles of combination treatment. A total of 2 patients developed CLL progression after 24 cycles of combination therapy, and 1 developed RT while on combination therapy. Grade 3/4 neutropenia occurred in $43 \%$ and atrial fibrillation in $8 \%$. The doses of ibrutinib and venetoclax were reduced in $57 \%$ and $35 \%$ of patients, respectively.

The UK CLARITY phase 2 study also evaluated the combination of ibrutinib (administered alone for the first 8 weeks) and venetoclax in 50 patients with relapsed/refractory CLL ${ }^{78}$. Patients had received 1-6 prior therapies (median 1), 20\% had del17p, $25 \%$ del11q, and $75 \%$ unmutated $I G H V^{79}$. Duration of therapy was based on peripheral blood and bone marrow assessments after 6,12 , and 24 cycles of combination treatment. Venetoclax was administered for a maximum of 24 cycles, but both drugs could be stopped after 12 cycles of combination therapy if both blood and marrow MRD negativity were attained after 6 cycles of combination therapy. The ORR was $89 \%(n=49)$ after 12 cycles of combination therapy, including CR/CRi in $51 \%$ and PR in $38 \%$. As in the MDACC trial, responses deepened over time, with the rate of undetectable MRD in the bone marrow increasing from $40 \%$ after 12 cycles of combination treatment to $48 \%$ after 24 cycles.

Another approach being pursued by investigators at MDACC is the addition of venetoclax as "consolidation" in high-risk patients already on ibrutinib for $\geq 1$ year and responding, but with detectable disease. The maximum duration of combination therapy is 2 years. Venetoclax is stopped after two consecutive undetectable MRD assessments in the bone marrow; ibrutinib can continue. Updated results from this study (on 45 patients) were recently presented ${ }^{80}$. A total of two patients $(4 \%)$ were in $\mathrm{CR}$ at venetoclax initiation, and $45 \%$ after 1 year. After 6 and 12 months of combination therapy, 40\% (17/42) and 64\% (21/33), respectively, had achieved bone marrow MRD clearance. Treatment has been well tolerated. Only one patient had CLL progression after 18 months of combination therapy.

\section{Triple targeted therapy regimens}

Given the successes of ibrutinib plus venetoclax regimens ${ }^{74,78}$ and of each of these drugs individually when combined with obinutuzumab $^{19,67}$, the advent of "triple" regimens incorporating a BTK inhibitor, venetoclax, and obinutuzumab was a logical next step. The group at OSU studied the combination of ibrutinib, venetoclax, and obinutuzumab given for a finite duration in patients with both treatment-naïve $(n=25)$ and relapsed/refractory CLL $(n=25)^{81}$. Initiation of the 3 agents was staggered so that obinutuzumab was administered in cycles 1 through 8, ibrutinib in cycles 2 through 14, and venetoclax in cycles 3 through $14^{82}$. Infusion reactions $(66 \%$, all grades $1 / 2)$, hypertension $(70 \%, 32 \%$ grade $3 / 4)$, neutropenia $(76 \%$, $56 \%$ grade $3 / 4)$, and thrombocytopenia $(80 \%, 34 \%$ grade $3 / 4)$ were extremely frequent. With 24.2 months of follow-up (median) of the treatment-naïve cohort and 21.5 months (median) for the relapsed/refractory cohort, the ORRs at EOT were $84 \%$ and $88 \%$, respectively. MRD eradication in both blood and marrow at EOT occurred in $67 \%$ and $50 \%$ of patients, respectively, in the treatment-naïve and relapsed/refractory groups, while $28 \%$ of patients were in MRD-negative (blood and marrow) $\mathrm{CR}$ at EOT in each cohort. Interestingly, in this trial, the ORRs mid-therapy (i.e. at the end of cycle 8) were higher than those at EOT in both treatment-naïve and relapsed/refractory patients. This was also true of the rate of MRD clearance in the relapsed/refractory cohort, but not in the treatment-naive cohort.

Investigators from the DFCI are testing the combination of acalabrutinib, venetoclax, and obinutuzumab (AVO) in the upfront setting $(n=44)^{83}$. Baseline characteristics as recently presented include a median age of 63, TP53 aberrations in $39 \%$, del11q in $27 \%$, complex karyotype in $20 \%$, and unmutated $I G H V$ in $66 \%$ of patients. In this study, acalabrutinib commences on cycle 1 , day 1 , and obinutuzumab (for 6 cycles) begins in cycle 2 , while venetoclax is initiated in cycle 4 and continued for 12 cycles. Patients can discontinue all therapy if MRD negative in the bone marrow after 15 cycles; those not achieving this (primary endpoint) continue acalabrutinib and venetoclax to complete 24 cycles. The ORR was $97 \%$ even before the initiation of venetoclax and improved further to $100 \%(43 \%$ $\mathrm{CR} / \mathrm{CRi}$ ) at later time points. After 15 cycles, by ITT analysis, $78 \%$ had achieved undetectable MRD in the bone marrow (31\% CR with undetectable bone marrow MRD) and $84 \%$ in 
the peripheral blood. All 10 patients with TP53 aberrations who completed 15 cycles responded, and responses did not differ by $I G H V$ mutation status. No patients had disease progression after a median follow-up of 19 months, and 11 discontinued therapy per protocol after attaining undetectable bone marrow MRD after 15 cycles. A similar combination trial (NCT04169737) has been initiated at MDACC in which patients with either relapsed/ refractory or high-risk, previously untreated CLL/SLL are randomly assigned to receive either early or late obinutuzumab (all patients receive acalabrutinib and venetoclax) to address the role of CD20 targeting in this context.

The combination of zanubrutinib, obinutuzumab, and venetoclax, the so-called BOVen regimen, has also been studied in the frontline setting $(n=39)^{84}$. A total of $72 \%$ of patients had unmutated $I G H V$, and $15.4 \%$ had del17p or TP53 $3^{\text {mut }}$. Both zanubrutinib and obinutuzumab began in cycle 1 , obinutuzumab was given for 8 cycles, and venetoclax was initiated in cycle 3. At a median follow-up of 14+ months, the rates of undetectable MRD in the bone marrow (primary endpoint) and peripheral blood were $84 \%$ and $92 \%$, respectively. A total of 29 patients $(77 \%)$ were able to discontinue therapy per protocol, having achieved undetectable MRD in both blood ( 2 consecutive samples) and marrow.

\section{Venetoclax resistance and salvaging patients who fail venetoclax}

While all the underlying mechanisms of resistance to venetoclax in CLL have yet to be elucidated, the discovery that acquisition of the G101V mutation in BCL-2, greatly reducing its affinity for venetoclax, could pre-date and lead to clinical disease progression in some patients was an important breakthrough ${ }^{85}$. These investigators later reported the co-occurrence of multiple other BCL-2 mutations, e.g. at Asp103, along with G101V in the context of disease progression on venetoclax ${ }^{86}$. Others have reported clonal evolution on venetoclax therapy, including mutations in $B T G 1$ and homozygous deletions of $C D K N 2 A / B$, as well as BRAF mutations and amplification of $P D-L 1$ as possible mechanisms ${ }^{87}$. Mcl-1 overexpression and mitochondrial reprogramming, involving regulators of transcription and cellular energy metabolism, have also been implicated as driving venetoclax resistance in lymphoid malignancies ${ }^{88}$.

With the increasing use of ibrutinib or acalabrutinib and venetoclax earlier in therapy, a scenario one is increasingly likely to encounter is that of patients who have failed both BTK and BCL-2 inhibition. Treatment options are very limited in this situation, an important area of unmet medical need. The results of chimeric antigen receptor-modified T-cell (CAR T-cell) therapy in CLL were underwhelming after the initial enthusiasm surrounding $\mathrm{it}^{89}$, and no CAR T-cell product is approved at present for patients with CLL; however, data presented at the 2020 ASH annual meeting on the investigational CD19-directed CAR T-cell product lisocabtagene maraleucel (liso-cel) appear promising, with a best ORR of $82 \%(\mathrm{CR} / \mathrm{CRi}$ in $45 \%)$ and rapid clearance of both blood and marrow MRD in most patients ${ }^{90}$. The patient population $(n=23)$ studied was a heavily pre-treated one (median 6 prior therapies), with all patients having received prior ibrutinib and over half having received venetoclax as well. The results with this product in combination with ibrutinib in a very similar patient population ( $n=19$ ) have been similarly encouraging ${ }^{91}$. Albeit early, anti-CD19 CAR NK (natural killer)-cells derived from cord blood have shown efficacy in patients with relapsed/refractory non-Hodgkin's lymphoma or CLL without cytokine release syndrome, neurotoxicity, or graft-versus-host disease ${ }^{92}$.

An important multi-center, retrospective study identified 326 patients with CLL who discontinued venetoclax $(96 \%$ in the relapsed/refractory setting $)^{93}$. Prior to venetoclax initiation, $82 \%$ of the patients had unmutated $I G H V, 47 \%$ del17p, $45 \%$ TP $53^{\text {mut }}$, $39 \%$ complex karyotype, $23 \% B T K^{\text {mut }}$, and $10 \% P L C G 2^{\text {mut. The }}$ median number of therapies prior to venetoclax was 3. Progressive CLL or RT was the reason for discontinuation of venetoclax in $50 \%$. BTK inhibitor therapy following venetoclax discontinuation was highly effective in BTK inhibitor-naïve patients (ORR 84\%; estimated median PFS 32 months). The ORR to BTK inhibition was $54 \%$ in BTK inhibitor-exposed patients, with the median PFS ranging from not reached in BTK inhibitor-intolerant patients to 4 months in resistant patients. Responses to PI3K inhibitor therapy (ORR 47\%) were not durable (median PFS 5 months), even though all patients were PI3K inhibitor naïve. A total of 18 patients received CAR T-cell therapy and $66 \%$ responded (median PFS 9 months), while median PFS was not reached for the 19 patients who underwent allogeneic hematopoietic cell transplantation (allo-HCT).

\section{Conclusions}

The BTK inhibitors and venetoclax have revolutionized the treatment of CLL, with "cure" or long-term treatment-free remission now seeming a realistic goal, although RT remains a formidable therapeutic challenge. Acalabrutinib and zanubrutinib promise to make BTK inhibition safer while preserving the efficacy of ibrutinib, at least with the limited follow-up available to date. Reversible BTK inhibitors will hopefully address the problem of resistance to ibrutinib and acalabrutinib. Equally, the appeal of "time-limited", venetoclax-based therapy is obvious. The selection of upfront therapy needs to be tailored to the individual patient, as does the optimal sequencing of therapies. The ideal duration of "time-limited" therapy continues to be debated. After idelalisib, duvelisib was another PI3K inhibitor to receive FDA approval for relapsed/refractory CLL based on the demonstration of superior PFS versus ofatumumab in the DUO trial ${ }^{94}$, but the immune-mediated toxicities of this class of agents have precluded their widespread use. Nevertheless, development of umbralisib, a PI3K inhibitor with an apparently cleaner safety profile, in combination with ublituximab, a CD20 monoclonal antibody from the same company, continues, and positive results from the pivotal UNITY-CLL trial were recently presented (Table 3) $)^{95,96}$. In general, combination strategies have resulted in high rates of CR with undetectable MRD. CAR T-cells and CAR NK-cells appear promising as well and will likely be best positioned after failure of BTK inhibitor(s) and venetoclax. 


\section{Table 3. Results with the "U2" (umbralisib + ublituximab) regimen in relapsed/refractory CLL.}

\begin{tabular}{|c|c|c|c|c|c|}
\hline Study design & Regimen & Patients & Efficacy & Safety & Reference \\
\hline $\begin{array}{l}\text { Phase } 1 / 1 \mathrm{~b}, \\
\text { multi-center } \\
\text { trial in pts with } \\
\text { R/R B-NHL or } \\
\text { CLL with dose } \\
\text { escalation and } \\
\text { expansion } \\
\text { portions; TN } \\
\text { CLL allowed in } \\
\text { phase } 1 \mathrm{~b}\end{array}$ & $\begin{array}{l}\text { Umbralisib daily PO } \\
\text { continuously; ublituximab } \\
\text { IV on } \mathrm{d} 1,8,15 \text { of } \mathrm{C} 1, \mathrm{~d} 1 \\
\text { of } \mathrm{C} 2-\mathrm{C} 6 \text {, and then } \mathrm{d} 1 \\
\text { every } 3 \text { cycles (C7-C12) }\end{array}$ & $\begin{array}{l}\mathrm{n}=75 \text { (22 pts } \\
\text { with CLL/SLL, } \\
53 \text { with B-NHL). } \\
9 \mathrm{CLL} / \mathrm{SLL} \text { pts } \\
\text { with del17p, } 6 \\
\text { BTKi-exposed; } \\
\text { median } 2 \text { prior } \\
\text { therapies (0-7) }\end{array}$ & $\begin{array}{l}\mathrm{n}=21 . \text { ORR } 62 \% \text { ( } 10 \% \\
\mathrm{CR}+52 \% \mathrm{PR}) ; \text { ORR } \\
40 \% \text { in BTKi-exposed } \\
\text { pts. Median DOR } 25.89 \\
\mathrm{~m} \text {; median PFS } 27.57 \\
\text { m. Median treatment } \\
\text { duration } 11 \mathrm{~m} . \\
\text { RP2D: } 900 \mathrm{mg} \\
\text { ublituximab and } 800 \mathrm{mg} \\
\text { micronized umbralisib }\end{array}$ & $\begin{array}{l}n=75 . \text { MTD not reached; } \\
1 \text { DLT (gr } 4 \text { neutropenia) in } \\
\text { a CLL/SLL pt. Gr } 3 / 4 \text { AEs: } \\
\text { diarrhea ( } 8 \% \text { ), neutropenia } \\
\text { (28\%, } 50 \% \text { in CLL/SLL pts), } \\
\text { pneumonia ( } 8 \% \text { ), abd pain } \\
\text { (7\%), transaminitis ( } 4 \%) \text {. } \\
2 \text { cases of pneumonitis, } 1 \\
\text { bx-proven colitis (median f/u } \\
7.4 \text { m) }\end{array}$ & 95 \\
\hline $\begin{array}{l}\text { Phase } 3 \text { trial } \\
\text { of U2 versus } \\
\text { obin-clb in pts } \\
\text { with TN or R/R } \\
\text { CLL }\end{array}$ & $\begin{array}{l}\text { Umbralisib } 800 \mathrm{mg} \\
\text { daily PO continuously; } \\
\text { ublituximab } 900 \mathrm{mg} \text { IV } \\
\text { on } \mathrm{d} 1 / 2,8,15 \text { of } \mathrm{C} 1 \text {, d1 } \\
\text { of C2-C6, and then d1 } \\
\text { every } 3 \text { cycles. Obin } \\
1,000 \mathrm{mg} \text { IV on d1/2, } 8 \text {, } \\
15 \text { of } \mathrm{C} 1, \mathrm{~d} 1 \text { of } \mathrm{C} 2-\mathrm{C} 6 \text {. } \\
\mathrm{Clb} 0.5 \mathrm{mg} / \mathrm{kg} \text { PO on d1 } \\
\text { and d } 15 \text { of C } 1-\mathrm{C} 6\end{array}$ & $\begin{array}{l}\mathrm{n}=421 \text { (210 U2 } \\
+211 \text { obin-clb). } \\
\text { Median age 67, } \\
240 \text { TN, } 181 \mathrm{R} / \mathrm{R} \\
\text { (median } 1 \text { prior } \\
\text { therapy). 10\% } \\
\text { with del17p, } \\
20 \% \text { del11q, } \\
56 \% \text { IGHV } \\
\text { unmutated }\end{array}$ & $\begin{array}{l}\text { Median PFS } 31.9 \mathrm{~m} \text { with } \\
\text { U2 (38.5 m for TN and } \\
19.5 \mathrm{~m} \text { for R/R) vs. } 17.9 \mathrm{~m} \\
\text { with obin-clb ( } 26.1 \mathrm{~m} \\
\text { for TN and } 12.9 \mathrm{~m} \text { for } \\
\text { R/R) after median f/u of } \\
36.2 \mathrm{~m} \text {. } 24-\mathrm{m} \text { PFS rates } \\
60.8 \% \text { with U2 and } 40.4 \% \\
\text { with obin-clb. ORR } 83.3 \% \\
\text { with U2 vs. 68.7\% with } \\
\text { obin-clb }\end{array}$ & $\begin{array}{l}\text { Gr } 3 / 4 \text { AEs of interest (U2 vs. } \\
\text { obin-clb): } \\
\text { neutropenia (30.6\% vs. } \\
34.7 \%) \text {, thrombocytopenia } \\
\text { (3.4\% vs. } 13.1 \%) \text {, diarrhea } \\
(12.1 \% \text { vs. } 2.5 \%) \text {, IRR (1.9\% } \\
\text { vs. } 3.5 \%) \text {, elevated liver } \\
\text { enzymes }(8.3 \% \text { vs. } 2 \%) \text {, } \\
\text { colitis (3.4\% vs. } 0 \%) \text {, and } \\
\text { pneumonitis ( } 2.9 \% \text { vs. } 0 \%)\end{array}$ & 96 \\
\hline
\end{tabular}

Abbreviations: abd, abdominal; AE, adverse event; B-NHL, B-cell non-Hodgkin's lymphoma; BTKi, Bruton's tyrosine kinase inhibitor; bx, biopsy; C, cycle; clb, chlorambucil; CLL, chronic lymphocytic leukemia; CR, complete response; d, day; DLT, dose-limiting toxicity; DOR, duration of response; f/u, follow-up; gr, grade; IRR, infusion-related reaction; IV, intravenous; MTD, maximum tolerated dose; obin, obinutuzumab; ORR, overall response rate; PFS, progression-free survival; PO, oral; PR, partial response; pts, patients; RP2D, recommended phase 2 dose; R/R, relapsed/refractory; SLL, small lymphocytic lymphoma;

TN, treatment-naïve.

1. Bose P, Gandhi V: Recent therapeutic advances in chronic lymphocytic leukemia [version 1; peer review: 2 approved]. F1000Res. 2017; 6: 1924 PubMed Abstract | Publisher Full Text | Free Full Text

2. Burger JA: Treatment of Chronic Lymphocytic Leukemia. N Engl J Med. 2020; 383(5): 460-73.

PubMed Abstract | Publisher Full Text

3. Byrd JC, Brown JR, O'Brien S, et al:: Ibrutinib versus ofatumumab in previously treated chronic lymphoid leukemia. N Engl J Med. 2014; 371(3): 213-23.

PubMed Abstract | Publisher Full Text | Free Full Text |

Faculty Opinions Recommendation

4. Burger JA, Tedeschi A, Barr PM, et al.: Ibrutinib as Initial Therapy for Patients with Chronic Lymphocytic Leukemia. N Engl J Med. 2015; 373(25): 2425-37.

PubMed Abstract | Publisher Full Text | Free Full Text |

Faculty Opinions Recommendation

5. Munir T, Brown JR, O'Brien S, et al:: Final analysis from RESONATE: Up to six years of follow-up on ibrutinib in patients with previously treated chronic lymphocytic leukemia or small lymphocytic lymphoma. Am J Hematol. 2019; 94(12): 1353-63.

PubMed Abstract | Publisher Full Text | Free Full Text | Faculty Opinions Recommendation

6. Burger JA, Barr PM, Robak T, et al.: Long-term efficacy and safety of firstline ibrutinib treatment for patients with CLL/SLL: 5 years of follow-up from the phase 3 RESONATE-2 study. Leukemia. 2020; 34(3): 787-98. PubMed Abstract | Publisher Full Text | Free Full Text | Faculty Opinions Recommendation

7. O'Brien SM, Jaglowski S, Byrd JC, et al:: Prognostic Factors for Complete Response to Ibrutinib in Patients With Chronic Lymphocytic Leukemia: A Pooled Analysis of 2 Clinical Trials. JAMA Oncol. 2018; 4(5): 712-6. PubMed Abstract | Publisher Full Text | Free Full Text
8. Strati P, Schlette EJ, Soto LMS, et al.: Achieving complete remission in CLL patients treated with ibrutinib: Clinical significance and predictive factors. Blood 2020; 135(7): 510-3.

PubMed Abstract | Publisher Full Text | Free Full Text

9. Ahn IE, Tian X, Wiestner A: Ibrutinib for Chronic Lymphocytic Leukemia with TP53 Alterations. N Engl J Med. 2020; 383(5): 498-500. PubMed Abstract | Publisher Full Text | Free Full Text

10. Woyach JA, Ruppert AS, Heerema NA, et al:: Ibrutinib Regimens versus Chemoimmunotherapy in Older Patients with Untreated CLL. N Engl J Med. 2018; 379(26): 2517-28.

PubMed Abstract | Publisher Full Text | Free Full Text |

Faculty Opinions Recommendation

11. Shanafelt TD, Wang XV, Kay NE, et al:: Ibrutinib-Rituximab or Chemoimmunotherapy for Chronic Lymphocytic Leukemia. N Engl J Med. 2019; 381(5): 432-43.

PubMed Abstract | Publisher Full Text | Free Full Text |

Faculty Opinions Recommendation

12. Thompson PA, Tam CS, O'Brien SM, et al:: Fludarabine, cyclophosphamide, and rituximab treatment achieves long-term disease-free survival in IGHV-mutated chronic lymphocytic leukemia. Blood. 2016; 127(3): 303-9. PubMed Abstract | Publisher Full Text | Free Full Text

13. Shanafelt TD, Wang V, Kay NE, et al:: Ibrutinib and Rituximab Provides Superior Clinical Outcome Compared to FCR in Younger Patients with Chronic Lymphocytic Leukemia (CLL): Extended Follow-up from the E1912 Trial. Blood. 2019; 134(1): 33 . 2019; 134(1): 33.
Publisher Full Text

14. Jain N, Thompson PA, Burger JA, et al: Ibrutinib, Fludarabine, Cyclophosphamide, and Obinutuzumab (iFCG) for First-Line Treatment of IGHV-Mutated CLL and without Del(17p)/Mutated TP53. Blood. 2019; 134(1): 357. Publisher Full Text 
15. Davids MS, Brander DM, Kim HT, et al.: Ibrutinib plus fludarabine, cyclophosphamide, and rituximab as initial treatment for younger patients with chronic lymphocytic leukaemia: A single-arm, multicentre, phase 2 trial. Lancet Haematol. 2019; 6(8): e419-e428.

PubMed Abstract | Publisher Full Text | Free Full Text

16. Burger JA, Sivina M, Jain N, et al.: Randomized trial of ibrutinib vs ibrutinib plus rituximab in patients with chronic lymphocytic leukemia. Blood. 2019; 133(10): 1011-9.

PubMed Abstract | Publisher Full Text | Free Full Text

17. Goede V, Fischer K, Busch R, et al.: Obinutuzumab plus chlorambucil in patients with CLL and coexisting conditions. N Engl J Med. 2014; 370(12): 1101-10.

PubMed Abstract | Publisher Full Text | Faculty Opinions Recommendation

18. Kohrt HE, Sagiv-Barfi I, Rafiq S, et al:: Ibrutinib antagonizes rituximabdependent NK cell-mediated cytotoxicity. Blood. 2014; 123(12): 1957-60. PubMed Abstract | Publisher Full Text | Free Full Text

19. Moreno C, Greil R, Demirkan F, et al:: Ibrutinib plus obinutuzumab versus chlorambucil plus obinutuzumab in first-line treatment of chronic lymphocytic leukaemia (iLLUMINATE): A multicentre, randomised, open-label, phase 3 trial. Lancet Oncol. 2019; 20(1): 43-56.

PubMed Abstract | Publisher Full Text | Faculty Opinions Recommendation

20. Coutre SE, Byrd JC, Hillmen P, et al.: Long-term safety of single-agent ibrutinib in patients with chronic lymphocytic leukemia in 3 pivotal studies. Blood Adv. 2019; 3(12): 1799-807.

PubMed Abstract | Publisher Full Text | Free Full Text

21. Mato AR, Nabhan C, Thompson MC, et al: Toxicities and outcomes of 616 ibrutinib-treated patients in the United States: A real-world analysis. Haematologica. 2018; 103(5): 874-9.

PubMed Abstract | Publisher Full Text | Free Full Text

22. Leong DP, Caron F, Hillis $\mathrm{C}$, et al.: The risk of atrial fibrillation with ibrutinib use: A systematic review and meta-analysis. Blood. 2016; 128(1): 138-40. PubMed Abstract | Publisher Full Text

23. Brown JR, Moslehi J, O'Brien S, et al:: Characterization of atrial fibrillation adverse events reported in ibrutinib randomized controlled registration trials. Haematologica. 2017; 102(10): 1796-805.

PubMed Abstract | Publisher Full Text | Free Full Text

24. Baptiste F, Cautela J, Ancedy $Y$, et al:: High incidence of atrial fibrillation in patients treated with ibrutinib. Open Heart. 2019; 6(1): e001049. PubMed Abstract | Publisher Full Text | Free Full Text

25. Wiczer TE, Levine LB, Brumbaugh J, et al:: Cumulative incidence, risk factors, and management of atrial fibrillation in patients receiving ibrutinib. Blood Adv 2017; 1(20): 1739-48.

PubMed Abstract | Publisher Full Text | Free Full Text

26. Lampson BL, Yu L, Glynn RJ, et al:: Ventricular arrhythmias and sudden death in patients taking ibrutinib. Blood. 2017; 129(18): 2581-2584. PubMed Abstract | Publisher Full Text | Free Full Text

27. Guha $\mathrm{A}$, Derbala $\mathrm{MH}$, Zhao Q, et al.: Ventricular Arrhythmias Following Ibrutinib Initiation for Lymphoid Malignancies. J Am Coll Cardiol. 2018; 72(6): 697-698. PubMed Abstract | Publisher Full Text | Free Full Text

28. Dickerson T, Wiczer T, Waller A, et al.: Hypertension and incident cardiovascular events following ibrutinib initiation. Blood. 2019; 134(22): 1919-1928.

PubMed Abstract | Publisher Full Text | Free Full Text |

Faculty Opinions Recommendation

29. Ekman N, Lymboussaki A, Västrik I, et al.: Bmx tyrosine kinase is specifically expressed in the endocardium and the endothelium of large arteries. Circulation. 1997; 96(6): 1729-32.

PubMed Abstract | Publisher Full Text

30. McMullen JR, Boey EJH, Ooi JYY, et al:: Ibrutinib increases the risk of atrial fibrillation, potentially through inhibition of cardiac PI3K-Akt signaling. Blood. 2014; 124(25): 3829-30.

PubMed Abstract | Publisher Full Text

31. Bye AP, Unsworth AJ, Desborough MJ, et al:: Severe platelet dysfunction in NHL patients receiving ibrutinib is absent in patients receiving acalabrutinib. Blood Adv. 2017; 1(26): 2610-2623.

PubMed Abstract | Publisher Full Text | Free Full Text

32. Chen J, Kinoshita T, Gururaja T, et al.: The effect of Bruton's tyrosine kinase (BTK) inhibitors on collagen-induced platelet aggregation, BTK, and tyrosine kinase expressed in hepatocellular carcinoma (TEC). Eur J Haematol. 2018. PubMed Abstract | Publisher Full Text

33. Dobie G, Kuriri FA, Omar MMA, et al:: Ibrutinib, but not zanubrutinib, induces platelet receptor shedding of GPIb-IX-V complex and integrin $\alpha_{11 b} \beta_{3}$ in mice and humans. Blood Adv. 2019; 3(24): 4298-4311. PubMed Abstract | Publisher Full Text | Free Full Text

34. Rogers KA, Mousa L, Zhao Q, et al:: Incidence of opportunistic infections during ibrutinib treatment for B-cell malignancies. Leukemia. 2019; 33(10): 2527-2530.

PubMed Abstract | Publisher Full Text | Free Full Text |

Faculty Opinions Recommendation
35. Ruchlemer R, Ben-Ami R, Bar-Meir M, et al:: Ibrutinib-associated invasive fungal diseases in patients with chronic lymphocytic leukaemia and non-Hodgkin lymphoma: An observational study. Mycoses. 2019; 62(12): 1140-1147. PubMed Abstract | Publisher Full Text

36. Bercusson A, Colley T, Shah A, et al.: Ibrutinib blocks Btk-dependent NF-kB and NFAT responses in human macrophages during Aspergillus fumigatus phagocytosis. Blood. 2018; 132(18): 1985-8.

PubMed Abstract | Publisher Full Text | Free Full Text |

Faculty Opinions Recommendation

37. Blez D, Blaize M, Soussain C, et al:: Ibrutinib induces multiple functional defects in the neutrophil response against Aspergillus fumigatus.

Haematologica. 2020; 105(2): 478-89.

PubMed Abstract | Publisher Full Text | Free Full Text |

Faculty Opinions Recommendation

38. Woyach J, Huang Y, Rogers K, et al.: Resistance to Acalabrutinib in CLL Is Mediated Primarily By BTK Mutations. Blood. 2019; 134(Supplement_1): 504 Publisher Full Text

39. Woyach JA, Furman RR, Liu TM, et al.: Resistance mechanisms for the Bruton's tyrosine kinase inhibitor ibrutinib. N Engl J Med. 2014; 370(24): 2286-94. PubMed Abstract | Publisher Full Text | Free Full Text

40. CSharman JP, Egyed M, Jurczak W, et al:: Acalabrutinib with or without obinutuzumab versus chlorambucil and obinutuzmab for treatment-naive chronic lymphocytic leukaemia (ELEVATE TN): a randomised, controlled, phase 3 trial. Lancet. 2020; 395(10232): 1278-91.

PubMed Abstract | Publisher Full Text | Faculty Opinions Recommendation

41. Woyach JA, Blachly JS, Rogers KA, et al:: Acalabrutinib plus Obinutuzumab in Treatment-Naïve and Relapsed/Refractory Chronic Lymphocytic Leukemia. Cancer Discov. 2020; 10(3): 394-405.

PubMed Abstract | Publisher Full Text

42. Ghia P, Pluta A, Wach M, et al.: ASCEND: Phase III, Randomized Trial of Acalabrutinib Versus Idelalisib Plus Rituximab or Bendamustine Plus Rituximab in Relapsed or Refractory Chronic Lymphocytic Leukemia. J Clin Oncol. 2020; 38(25): 2849-61.

PubMed Abstract | Publisher Full Text | Faculty Opinions Recommendation

43. Ghia P, Pluta A, Wach M, et al.: Acalabrutinib Vs Idelalisib Plus Rituximab or Bendamustine Plus Rituximab in Relapsed/Refractory Chronic Lymphocytic Leukemia: Ascend Final Results. Blood. 2020; 136(S1): 3140. Reference Source

44. Byrd JC, Wierda WG, Schuh A, et al.: Acalabrutinib monotherapy in patients with relapsed/refractory chronic lymphocytic leukemia: Updated phase 2 results. Blood. 2020; 135(15): 1204-13. PubMed Abstract | Publisher Full Text | Free Full Text

45. A Awan FT, Schuh A, Brown JR, et al:: Acalabrutinib monotherapy in patients with chronic lymphocytic leukemia who are intolerant to ibrutinib. Blood Adv. 2019; 3(9): 1553-62.

PubMed Abstract | Publisher Full Text | Free Full Text

Faculty Opinions Recommendation

46. Tam CS, Trotman J, Opat S, et al.: Phase 1 study of the selective BTK inhibitor zanubrutinib in B-cell malignancies and safety and efficacy evaluation in CLL. Blood. 2019; 134(11): 851-9.

PubMed Abstract | Publisher Full Text | Free Full Text |

Faculty Opinions Recommendation

47. Hillmen P, Brown JR, Eichhorst BF, et al:: ALPINE: Zanubrutinib versus ibrutinib in relapsed/refractory chronic lymphocytic leukemia/small lymphocytic Iymphoma. Future Oncol. 2020; 16(10): 517-23.

PubMed Abstract | Publisher Full Text

48. Woyach JA, Ruppert AS, Guinn D, et al.: BTK ${ }^{\mathrm{C} 481 \mathrm{~S}}$-Mediated Resistance to Ibrutinib in Chronic Lymphocytic Leukemia. J Clin Oncol. 2017; 35(13): 1437-43.

PubMed Abstract | Publisher Full Text | Free Full Text

49. Mato AR, Pagel JM, Coombs CC, et al.: LOXO-305, A Next Generation, Highly Selective, Non-Covalent BTK Inhibitor in Previously Treated CLL/SLL: Results from the Phase 1/2 BRUIN Study. Blood. 2020; 136(S1): 542.

Reference Source

50. Allan JN, Patel K, Mato AR, et al.: Ongoing Results of a Phase 1B/2 DoseEscalation and Cohort-Expansion Study of the Selective, Noncovalent, Reversible Bruton'S Tyrosine Kinase Inhibitor, Vecabrutinib, in B-Cell Malignancies. Blood. 2019; 134(Supplement 1): 3041. Publisher Full Text

51. Woyach J, Stephens DM, Flinn IW, et al.: Final Results of Phase 1, Dose Escalation Study Evaluating ARQ 531 in Patients with Relapsed or Refractory B-Cell Lymphoid Malignancies. Blood. 2019; 134(Supplement_1): 4298. Publisher Full Text

52. Cull G, Simpson D, Opat S, et al.: Treatment with the Bruton Tyrosine Kinase Inhibitor Zanubrutinib (BGB-3111) Demonstrates High Overall Response Rate and Durable Responses in Patients with Chronic Lymphocytic Leukemia/Small Lymphocytic Lymphoma (CLL/SLL): Updated Results from a Phase 1/2 Trial. Blood. 2019; 134: 500

Publisher Full Text 
53. Brown JR, Robak T, Ghia P, et al:: Efficacy and Safety of Zanubrutinib in Patients with Treatment-Naïve (TN) Chronic Lymphocytic Leukemia (CLL) or Small Lymphocytic Lymphoma (SLL) with del(17p): Follow-up Results from Arm C of the SEQUOIA (BGB-3111-304) Trial. Blood. 2020; 136: Arm C Publisher Full Text

54. Stilgenbauer S, Eichhorst B, Schetelig J, et al:: Venetoclax in relapsed or refractory chronic lymphocytic leukaemia with $17 p$ deletion: A multicentre, open-label, phase 2 study. Lancet Oncol. 2016; 17(6): 768-78. PubMed Abstract | Publisher Full Text | Faculty Opinions Recommendation

55. Roberts AW, Davids MS, Pagel JM, et al.: Targeting BCL2 with Venetoclax in Relapsed Chronic Lymphocytic Leukemia. N Engl J Med. 2016; 374(4): 311-22. PubMed Abstract | Publisher Full Text | Free Full Text | Faculty Opinions Recommendation

56. Stilgenbauer S, Eichhorst B, Schetelig J, et al: Venetoclax for Patients With Chronic Lymphocytic Leukemia With $17 p$ Deletion: Results From the Full Population of a Phase II Pivotal Trial. J Clin Oncol. 2018; 36(19): 1973-80. PubMed Abstract | Publisher Full Text | Faculty Opinions Recommendation

57. Davids MS, Hallek M, Wierda W, et al:: Comprehensive Safety Analysis of Venetoclax Monotherapy for Patients with Relapsed/Refractory Chronic Lymphocytic Leukemia. Clin Cancer Res. 2018; 24(18): 4371-9. PubMed Abstract | Publisher Full Text | Faculty Opinions Recommendation

58. Roberts AW, Ma S, Kipps TJ, et al:: Efficacy of venetoclax in relapsed chronic lymphocytic leukemia is influenced by disease and response variables. Blood 2019; 134(2): 111-22.

PubMed Abstract | Publisher Full Text | Free Full Text

59. - Seymour JF, Kipps TJ, Eichhorst B, et al.: Venetoclax-Rituximab in Relapsed or Refractory Chronic Lymphocytic Leukemia. N Engl J Med. 2018; 378(12): 1107-20.

PubMed Abstract | Publisher Full Text | Faculty Opinions Recommendation

60. Kater AP, Kipps TJ, Eichhorst B, et al:: Five-Year Analysis of Murano Study Demonstrates Enduring Undetectable Minimal Residual Disease (UMRD) in a Subset of Relapsed/Refractory Chronic Lymphocytic Leukemia (R/R CLL) Patients (Pts) Following Fixed-Duration Venetoclax-Rituximab (VenR) Therapy (Tx). Blood 2020; 136: 19-21. Reference Source

61. Jones JA, Mato AR, Wierda WG, et al:: Venetoclax for chronic lymphocytic leukaemia progressing after ibrutinib: An interim analysis of a multicentre, open-label, phase 2 trial. The Lancet Oncol. 2018; 19(1): 65-75. PubMed Abstract | Publisher Full Text | Free Full Text

62. Coutre S, Choi M, Furman RR, et al.: Venetoclax for patients with chronic lymphocytic leukemia who progressed during or after idelalisib therapy. Blood. 2018; 131(15): 1704-1711.

PubMed Abstract | Publisher Full Text | Free Full Text

63. Wierda WG, Byrd JC, Davids MS, et al:: Venetoclax for chronic lymphocytic leukaemia patients who progress after more than one B-cell receptor pathway inhibitor. Br J Haematol. 2019; 185(5): 961-966. PubMed Abstract | Publisher Full Text | Free Full Text

64. Lew TE, Anderson MA, Lin VS, et al.: Undetectable peripheral blood MRD should be the goal of venetoclax in CLL, but attainment plateaus after 24 months. Blood Adv. 2020; 4(1): 165-73.

PubMed Abstract | Publisher Full Text | Free Full Text | Faculty Opinions Recommendation

65. Mato AR, Roeker LE, Eyre TA, et al: A retrospective comparison of venetoclax alone or in combination with an anti-CD20 monoclonal antibody in R/R CLL. Blood Adv. 2019; 3(10): 1568-73.

PubMed Abstract | Publisher Full Text | Free Full Text

66. Flinn IW, Gribben JG, Dyer MJS, et al:: Phase 1b study of venetoclaxobinutuzumab in previously untreated and relapsed/refractory chronic lymphocytic leukemia. Blood. 2019; 133(26): 2765-2775. PubMed Abstract | Publisher Full Text | Free Full Text

67. Fischer $\mathrm{K}, \mathrm{Al}$-Sawaf $\mathrm{O}$, Bahlo J, et al:: Venetoclax and Obinutuzumab in Patients with CLL and Coexisting Conditions. N Engl J Med. 2019; 380(23): 2225-2236.

PubMed Abstract | Publisher Full Text | Faculty Opinions Recommendation

68. Fischer K, Ritgen M, Al-Sawaf O, et al:: Quantitative Analysis of Minimal Residual Disease (MRD) Shows High Rates of Undetectable MRD after FixedDuration Chemotherapy-Free Treatment and Serves As Surrogate Marker for Progression-Free Survival: A Prospective Analysis of the Randomized CLL14 Trial. Blood. 2019; 134(Supplement_1): 36.

Publisher Full Text

69. Howard SC, Jones DP, Pui CH, et al.: The tumor lysis syndrome. N Engl J Med. 2011; 364(19): 1844-54

PubMed Abstract | Publisher Full Text | Free Full Text

70. Al-Sawaf O, Zhang C, Robrecht S, et al.: Clonal Dynamics after VenetoclaxObinutuzumab Therapy: Novel Insights from the Randomized, Phase 3 CLL14 Trial. Blood. 2020; 136(Supplement_1): 22-23. Publisher Full Text

71. Al-Sawaf O, Zhang C, Tandon M, et al:: Venetoclax plus obinutuzumab versus chlorambucil plus obinutuzumab for previously untreated chronic lymphocytic leukaemia (CLL14): Follow-up results from a multicentre, openlabel, randomised, phase 3 trial. Lancet Oncol. 2020; 21(9): 1188-1200. PubMed Abstract | Publisher Full Text | Faculty Opinions Recommendation

72. Cervantes-Gomez F, Lamothe B, Woyach JA, et al.: Pharmacological and Protein Profiling Suggests Venetoclax (ABT-199) as Optimal Partner with Ibrutinib in Chronic Lymphocytic Leukemia. Clin Cancer Res. 2015; 21(16): 3705-15. PubMed Abstract | Publisher Full Text | Free Full Text

73. Deng J, Isik E, Fernandes SM, et al.: Bruton's tyrosine kinase inhibition increases BCL-2 dependence and enhances sensitivity to venetoclax in chronic lymphocytic leukemia. Leukemia. 2017; 31(10): 2075-2084. PubMed Abstract | Publisher Full Text | Free Full Text

74. Jain N, Keating M, Thompson P, et al:: Ibrutinib and Venetoclax for First-Line Treatment of CLL. N Engl J Med. 2019; 380(22): 2095-2103. PubMed Abstract | Publisher Full Text

75. Jain N, Keating MJ, Thompson PA, et al.: Combined Ibrutinib and Venetoclax for First-Line Treatment for Patients with Chronic Lymphocytic Leukemia (CLL): Focus on MRD Results. Blood. 2020; 136(Supplement_1): 42-43. Publisher Full Text

76. Wierda WG, Tam CS, Allan JN, et al.: Ibrutinib (Ibr) Plus Venetoclax (Ven) for First-Line Treatment of Chronic Lymphocytic Leukemia (CLL)/Small Lymphocytic Lymphoma (SLL): 1-Year Disease-Free Survival (DFS) Results From the MRD Cohort of the Phase 2 CAPTIVATE Study. Blood. 2020; 136(Supplement_1): 16-17.

Publisher Full Text

77. Jain N, Keating MJ, Thompson PA, et al.: Combined Ibrutinib and Venetoclax in Patients with Relapsed/Refractory (R/R) Chronic Lymphocytic Leukemia (CLL). Blood. 2019; 134(Supplement_1): 359. Publisher Full Text

78. Hillmen P, Rawstron AC, Brock K, et al:: Ibrutinib Plus Venetoclax in Relapsed/ Refractory Chronic Lymphocytic Leukemia: The CLARITY Study. J Clin Oncol. 2019; 37(30): 2722-2729.

PubMed Abstract | Publisher Full Text | Free Full Text

79. Hillmen $\mathrm{P}$, Boucher $\mathrm{RH}$, Webster $\mathrm{N}$, et al:: Continued Long Term Responses to Ibrutinib + Venetoclax Treatment for Relapsed/Refractory CLL in the Blood Cancer UK TAP Clarity Trial. Blood. 2020; 136(Supplement 1): 17-18. Publisher Full Text

80. Thompson PA, Ferrajoli A, Jain N, et al:: The Addition of Venetoclax to lbrutinib Achieves a High Rate of Undetectable Minimal Residual Disease in Patients with High-Risk CLL. Blood. 2020; 136(Supplement 1): 28-29. Publisher Full Text

81. Rogers KA, Huang Y, Ruppert AS, et al.: Phase 2 Study of Combination Obinutuzumab, Ibrutinib, and Venetoclax in Treatment-Naive and Relapsed/ Refractory Chronic Lymphocytic Leukemia. Blood. 2018; 132(Supplement 1): 693. Publisher Full Text

82. Rogers KA, Huang Y, Ruppert AS, et al:: Phase 1b study of obinutuzumab, ibrutinib, and venetoclax in relapsed and refractory chronic lymphocytic leukemia. Blood. 2018; 132(15): 1568-1572. PubMed Abstract | Publisher Full Text | Free Full Text

83. Davids MS, Lampson BL, Tyekucheva S, et al:: Updated Safety and Efficacy Results from a Phase 2 Study of Acalabrutinib, Venetoclax and Obinutuzumab (AVO) for Frontline Treatment of Chronic Lymphocytic Leukemia (CLL). Blood. 2020; 136(Supplement 1): 20-21. Publisher Full Text

84. Soumerai JD, Mato AR, Carter J, et al.: MRD-Driven Time Limited Therapy with Zanubrutinib, Obinutuzumab, and Venetoclax (BOVen) in Previously Untreated Chronic Lymphocytic Leukemia. Blood. 2020; 136(S1): 1307. Reference Source

85. Blombery P, Anderson MA, Gong J, et al.: Acquisition of the Recurrent Gly101Val Mutation in BCL2 Confers Resistance to Venetoclax in Patients with Progressive Chronic Lymphocytic Leukemia. Blood. 2018; 132(Supplement 1): LBA-7. Publisher Full Text

86. Blombery $\mathrm{P}$, Thompson ER, Nguyen $\mathrm{T}$, et al:: Multiple BCL2 mutations cooccurring with Gly101Val emerge in chronic lymphocytic leukemia progression on venetoclax. Blood. 2020; 135(10): 773-777. PubMed Abstract | Publisher Full Text | Free Full Text

87. Herling CD, Abedpour N, Weiss J, et al:: Clonal dynamics towards the development of venetoclax resistance in chronic lymphocytic leukemia. Nat Commun. 2018; 9(1): 727

PubMed Abstract | Publisher Full Text | Free Full Text | Faculty Opinions Recommendation

88. Guièze R, Liu VM, Rosebrock D, et al.: Mitochondrial Reprogramming Underlies Resistance to BCL-2 Inhibition in Lymphoid Malignancies. Cancer Cell. 2019; 36(4): 369-384. e13.

PubMed Abstract | Publisher Full Text | Free Full Text | Faculty Opinions Recommendation

89. P Porter DL, Levine BL, Kalos M, et al:: Chimeric antigen receptor-modified T cells in chronic lymphoid leukemia. N Engl J Med. 2011; 365(8): 725-33. PubMed Abstract | Publisher Full Text | Free Full Text | Faculty Opinions Recommendation 
90. Siddiqi T, Soumerai JD, Dorritie KA, et al:: Updated Follow-up of Patients with Relapsed/Refractory Chronic Lymphocytic Leukemia/Small Lymphocytic Lymphoma Treated with Lisocabtagene Maraleucel in the Phase 1 Monotherapy Cohort of Transcend CLL 004, Including High-Risk and IbrutinibTreated Patients. Blood. 2020; 136(S1): 546. Reference Source

91. Wierda WG, Dorritie KA, Munoz J, et al.: Transcend CLL 004: Phase 1 Cohort of Lisocabtagene Maraleucel (liso-cel) in Combination with lbrutinib for Patients with Relapsed/Refractory (R/R) Chronic Lymphocytic Leukemia/Small Lymphocytic Lymphoma (CLL/SLL). Blood. 2020; 136(S1): 544. Reference Source

92. Liu E, Marin D, Banerjee P, et al.: Use of CAR-Transduced Natural Killer Cells in CD19-Positive Lymphoid Tumors. N Engl J Med. 2020; 382(6): 545-53. PubMed Abstract | Publisher Full Text | Free Full Text | Faculty Opinions Recommendation

93. Mato AR, Roeker LE, Jacobs R, et al.: Assessment of the Efficacy of Therapies Following Venetoclax Discontinuation in CLL Reveals BTK
Inhibition as an Effective Strategy. Clin Cancer Res. 2020; 26(14): 3589-3596. PubMed Abstract | Publisher Full Text | Faculty Opinions Recommendation

94. Flinn IW, Hillmen P, Montillo M, et al:: The phase $\mathbf{3}$ DUO trial: Duvelisib vs ofatumumab in relapsed and refractory CLL/SLL. Blood. 2018; 132(23): 2446-2455

PubMed Abstract | Publisher Full Text | Free Full Text

95. Lunning M, Vose J, Nastoupil L, et al:: Ublituximab and umbralisib in relapsed/refractory B-cell non-Hodgkin lymphoma and chronic lymphocytic leukemia. Blood. 2019; 134(21): 1811-1820.

PubMed Abstract | Publisher Full Text | Free Full Text |

Faculty Opinions Recommendation

96. Gribben JG, Jurczak WJ, Jacobs R, et al:: Umbralisib Plus Ublituximab (U2) Is Superior to Obinutuzumab Plus Chlorambucil $(\mathrm{O}+\mathrm{Chl})$ in Patients with Treatment Naïve (TN) and Relapsed/Refractory (R/R) Chronic Lymphocytic Leukemia (CLL): Results from the Phase 3 Unity-CLL Study. Blood. 2020; 136(S1): 543

Reference Source 